\title{
Molecular Structures of Enantiomerically-Pure (S)-2-(Triphenylsilyl)- and (S)-2-(Methyldiphenylsilyl)pyrrolidinium Salts
}

\author{
Jonathan O. Bauer ${ }^{\dagger}$ and Carsten Strohmann * \\ Anorganische Chemie, Fakultät für Chemie und Chemische Biologie, Technische Universität Dortmund, \\ Otto-Hahn-Straße 6, D-44227 Dortmund, Germany; jonathan.bauer@ur.de \\ * Correspondence: carsten.strohmann@tu-dortmund.de \\ † Current address: Institut für Anorganische Chemie, Fakultät für Chemie und Pharmazie, \\ Universität Regensburg, Universitätsstraße 31, D-93053 Regensburg, Germany
}

Received: 31 October 2017; Accepted: 2 December 2017; Published: 6 December 2017

\begin{abstract}
Silyl-substituted pyrrolidines have gained increased interest for the design of new catalyst scaffolds. The molecular structures of four enantiomerically-pure 2-silylpyrrolidinium salts are reported. The perchlorate salts of (S)-2-(triphenylsilyl)pyrrolidine [(S)-1- $\left.\mathrm{HClO}_{4}\right]$ and $(S)$-2-(methyldiphenylsilyl)pyrrolidine $\left[(S)-2 \cdot \mathrm{HClO}_{4}\right]$, the trifluoroacetate $(S)-\mathbf{2} \cdot \mathrm{TFA}$, and the methanol-including hydrochloride $(S)-\mathbf{1} \cdot \mathrm{HCl} \cdot \mathrm{MeOH}$ were elucidated by $\mathrm{X}$-ray crystallography and discussed in terms of hydrogen-bond interactions.
\end{abstract}

Keywords: hydrogen bonds; silicon; 2-silylpyrrolidines; stereochemistry; X-ray crystallography

\section{Introduction}

In 2010, we and others reported on the enantioselective synthesis of 2-silylpyrrolidines as organocatalysts for the asymmetric Michael addition of aldehydes to nitroolefines [1,2]. Since then, some impressive developments in the catalyst design have been achieved, overcoming synthetic challenges and introducing pyrrolidinylsilanols as bifunctional hydrogen bond-directing organocatalysts $[3,4]$. The stereochemical information of 2-substituted silylpyrrolidines was introduced by asymmetric deprotonation of $\mathrm{N}$-(tert-butoxycarbonyl)pyrrolidine ( $\mathrm{N}$-Boc-pyrrolidine) with sec-butyllithium in the presence of $(-)$-sparteine $[5,6]$, followed by a substitution reaction with a silyl halide or methoxide as the electrophile. Concerning the first successful preparation of enantiomerically-pure (S)-2-(triphenylsilyl)pyrrolidine [(S)-1], we established an indirect synthetic route via intermediate formation of 2-(methoxydiphenylsilyl)- $\mathrm{N}$-Boc-pyrrolidine [1]. Recently, a detailed structural and kinetic investigation gave new insight into the structure-reactivity relation in enamines and iminium ions derived from 2-tritylpyrrolidine [7] and 2-(triphenylsilyl)pyrrolidine [8]. (S)-2-(Triphenylsilyl)pyrrolidine [(S)-1] and (S)-2-(methyldiphenylsilyl)pyrrolidine $[(S)-2]$ have already been structurally characterized in the form of their hydrochloride [1,2] and their hydrobromide salts [3] (Figure 1).<smiles>c1ccc([Si](c2ccccc2)(c2ccccc2)C2CCCN2)cc1</smiles>

$(S)-1$<smiles>C[Si](c1ccccc1)(c1ccccc1)C1CCCN1</smiles>

$(S)-2$

Figure 1. (S)-2-(triphenylsilyl)- [(S)-1] and (S)-2-(methyldiphenylsilyl)pyrrolidine [(S)-2]. 
Herein, we present the molecular structures of enantiomerically-pure (S)-2-(triphenylsilyl)-[(S)-1. $\left.\mathrm{HClO}_{4}\right]$ and (S)-2-(methyldiphenylsilyl)pyrrolidinium perchlorate [(S)-2. $\left.\mathrm{HClO}_{4}\right]$, which were obtained from the respective optically-pure chloride salts [1] by treatment with perchloric acid. In addition, we report on hydrogen-bonding motifs in the new enantiomerically-pure methanol inclusion compound (S)-1.HCl.MeOH and in the enantiomerically-pure trifluoroacetate (S)-2.TFA. Hydrogen bonding in enantiomerically-pure pyrrolidines is worth studying in order to explore new activation modes in organocatalytic transformations.

\section{Results and Discussion}

Compound (S)-1. $\mathrm{HClO}_{4}$ crystallized in the monoclinic crystal system, space group $P 2_{1}$, as colorless plates (Figure 2 and Table 1). The pyrrolidinyl nitrogen atom of $(S)-\mathbf{1} \cdot \mathrm{HClO}_{4}$ has been protonated by perchloric acid and is involved in hydrogen bonds to two perchlorate anions via $\mathrm{H}(1 \mathrm{~N})$ and $\mathrm{H}(2 \mathrm{~N})$. The hydrogen bond $\mathrm{N}-\mathrm{H}(1 \mathrm{~N}) \cdots \mathrm{O}(1)$ is slightly stronger $[\mathrm{N}-\mathrm{H}(1 \mathrm{~N}) 0.911 \AA, \mathrm{H}(1 \mathrm{~N}) \cdots \mathrm{O}(1)$ $\left.1.966 \AA, \mathrm{N} \cdots \mathrm{O}(1) 2.845 \AA, \mathrm{N}-\mathrm{H}(1 \mathrm{~N}) \cdots \mathrm{O}(1) 161.79^{\circ}\right]$ than the interaction between $\mathrm{H}(2 \mathrm{~N})$ and $\mathrm{O}(2)$ $\left[\mathrm{N}-\mathrm{H}(2 \mathrm{~N}) 0.773 \AA, \mathrm{H}(2 \mathrm{~N}) \cdots \mathrm{O}(2) 2.230 \AA, \mathrm{N} \cdots \mathrm{O}(2) 2.940 \AA, \mathrm{N}-\mathrm{H}(2 \mathrm{~N}) \cdots \mathrm{O}(2) 152.82^{\circ}\right]$. The C-Si bond lengths of the triphenylsilyl moiety are comparable to those found in the hydrochloride species $(S)-\mathbf{1} \cdot \mathrm{HCl}[1]$ and in other triphenyl-substituted silanes [9,10]. The C(19)-Si bond between silicon and the heterocyclic carbon atom amounts to 1.9111(15) $\AA$ and is in the characteristic range for 2-(triphenylsilyl)pyrrolidines [1] (Figure 2). This significantly longer bond compared to the respective $\mathrm{C}-\mathrm{C}$ bond in the carbon analogue 2-tritylpyrrolidine was considered a crucial parameter for the higher reactivity of (S)-1 in enamine catalysis [1].

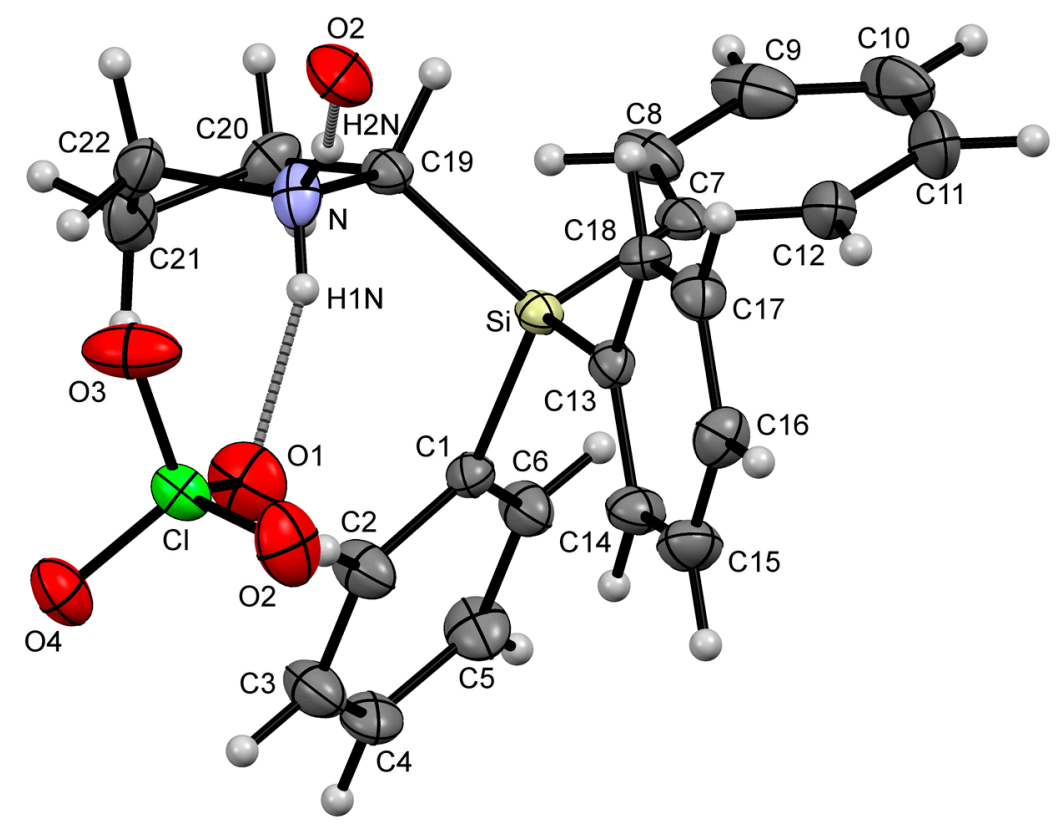

Figure 2. Part of the crystal structure (ORTEP plot) of compound (S)-1 $\cdot \mathrm{HClO}_{4}$ in the crystal, with the displacement ellipsoids set at the $50 \%$ probability level. Selected bond lengths $(\AA)$ and angles $\left(^{\circ}\right)$ : C(1)-Si 1.8727(15), C(7)-Si 1.8724(15), C(13)-Si 1.8595(15), C(19)-Si 1.9111(15), C(19)-N 1.5229(19), $\mathrm{C}(22)-\mathrm{N}$ 1.4999(19), Cl-O(1) 1.4376(12), Cl-O(2) 1.4305(13), Cl-O(3) 1.4316(13), Cl-O(4) 1.4217(12), C(13)-Si-C(7) 111.31(7), C(13)-Si-C(1) 111.55(7), C(7)-Si-C(1) 108.77(7), C(13)-Si-C(19) 108.01(6), $\mathrm{C}(7)-\mathrm{Si}-\mathrm{C}(19)$ 105.67(7), C(1)-Si-C(19) 111.39(6). Hydrogen bond N-H(1N) $\cdots \mathrm{O}(1)$ : N-H(1N) 0.911, $\mathrm{H}(1 \mathrm{~N}) \cdots \mathrm{O}(1) 1.966, \mathrm{~N} \cdots \mathrm{O}(1) 2.845, \mathrm{~N}-\mathrm{H}(1 \mathrm{~N}) \cdots \mathrm{O}(1)$ 161.79. Hydrogen bond $\mathrm{N}-\mathrm{H}(2 \mathrm{~N}) \cdots \mathrm{O}(2): \mathrm{N}-\mathrm{H}(2 \mathrm{~N})$ $0.773, \mathrm{H}(2 \mathrm{~N}) \cdots \mathrm{O}(2) 2.230, \mathrm{~N} \cdots \mathrm{O}(2) 2.940, \mathrm{~N}-\mathrm{H}(2 \mathrm{~N}) \cdots \mathrm{O}(2)$ 152.82. Symmetry transformations used to generate the equivalent atom $\mathrm{O}(2)$, hydrogen-bonded to $\mathrm{H}(2 \mathrm{~N}): 1-x, \frac{1}{2}+y,-z$. 
Table 1. Crystal data and structure refinement of compounds $(S)-\mathbf{1} \cdot \mathrm{HClO}_{4},(S)-\mathbf{1} \cdot \mathrm{HCl} \cdot \mathrm{MeOH},(S)-\mathbf{2} \cdot \mathrm{HClO}_{4}$, and (S)-2.TFA.

\begin{tabular}{|c|c|c|c|c|}
\hline Compound & $(S)-1 \cdot \mathrm{HClO}_{4}$ & $(S)-1 \cdot \mathrm{HCl} \cdot \mathrm{MeOH}$ & $(S)-2 \cdot \mathrm{HClO}_{4}$ & (S)-2.TFA \\
\hline Empirical formula & $\mathrm{C}_{22} \mathrm{H}_{24} \mathrm{ClNO}_{4} \mathrm{Si}$ & $\mathrm{C}_{23} \mathrm{H}_{28} \mathrm{ClNOSi}$ & $\mathrm{C}_{17} \mathrm{H}_{22} \mathrm{ClNO}_{4} \mathrm{Si}$ & $\mathrm{C}_{19} \mathrm{H}_{22} \mathrm{~F}_{3} \mathrm{NO}_{2} \mathrm{Si}$ \\
\hline Formula weight $\left[\mathrm{g} \cdot \mathrm{mol}^{-1}\right]$ & 429.96 & 398.00 & 367.90 & 381.47 \\
\hline Crystal system & Monoclinic & Orthorhombic & Monoclinic & Orthorhombic \\
\hline Space group & $P 2_{1}$ & $P 2_{1} 2_{1} 2_{1}$ & $P 2_{1}$ & $P 2_{1} 2_{1} 2_{1}$ \\
\hline$a[\AA ̊ \circ]$ & $8.1535(2)$ & $7.2981(3)$ & $9.6006(6)$ & $9.5760(14)$ \\
\hline$b[\AA]$ & $7.8737(2)$ & $11.7818(5)$ & $14.2054(8)$ & $9.7100(17)$ \\
\hline$c[\AA]$ & $16.9410(4)$ & 25.1513(11) & $13.3890(8)$ & $41.176(4)$ \\
\hline$\beta\left[^{\circ}\right]$ & $100.780(2)$ & 90 & $91.537(6)$ & 90 \\
\hline Volume $\left[\AA^{3}\right]$ & $1068.39(5)$ & 2162.63(16) & 1825.34(19) & $3828.7(9)$ \\
\hline$Z$ & 2 & 4 & 4 & 8 \\
\hline Density (calculated) $.9 \rho\left[\mathrm{g} \cdot \mathrm{cm}^{-3}\right]$ & 1.337 & 1.222 & 1.339 & 1.324 \\
\hline Absorption coefficient $\mu\left[\mathrm{mm}^{-1}\right]$ & 0.263 & 0.245 & 0.295 & 0.163 \\
\hline$F(000)$ & 452 & 848 & 776 & 1600 \\
\hline Crystal size $\left[\mathrm{mm}^{3}\right]$ & $0.20 \times 0.20 \times 0.10$ & $0.40 \times 0.30 \times 0.20$ & $0.20 \times 0.20 \times 0.10$ & $0.40 \times 0.20 \times 0.10$ \\
\hline Theta range for data collection $\theta\left[{ }^{\circ}\right]$ & $2.45-25.99$ & $2.37-26.00$ & $2.56-26.00$ & $2.18-25.00$ \\
\hline \multirow{3}{*}{ Index ranges } & $-10 \leq h \leq 10$ & $-9 \leq h \leq 9$ & $-11 \leq h \leq 11$ & $-11 \leq h \leq 11$ \\
\hline & $-9 \leq k \leq 9$ & $-14 \leq k \leq 14$ & $-17 \leq k \leq 17$ & $-11 \leq k \leq 10$ \\
\hline & $-20 \leq l \leq 20$ & $-31 \leq l \leq 30$ & $-16 \leq l \leq 16$ & $-47 \leq l \leq 48$ \\
\hline Reflections collected & $4 \overline{6}, 91 \overline{8}$ & $1 \overline{6,13 \overline{2}}$ & $2 \overline{8}, 99 \overline{3}$ & $4 \overline{1}, 44 \overline{1}$ \\
\hline Independent reflections & $4181\left(R_{\mathrm{int}}=0.0369\right)$ & $4244\left(R_{\mathrm{int}}=0.0388\right)$ & $7177\left(R_{\text {int }}=0.0540\right)$ & $6661\left(R_{\text {int }}=0.0425\right)$ \\
\hline Completeness to $\theta$ & $100.0 \%\left(\theta=25.99^{\circ}\right)$ & $99.9 \%\left(\theta=26.00^{\circ}\right)$ & $99.9 \%\left(\theta=26.00^{\circ}\right)$ & $99.3 \%\left(\theta=25.00^{\circ}\right)$ \\
\hline Max. and min. transmission & 0.9742 and 0.9493 & 0.9527 and 0.9085 & 0.9711 and 0.9433 & 0.9681 and 0.9376 \\
\hline Data/restraints/parameters & $4181 / 1 / 270$ & $4244 / 0 / 254$ & $7177 / 1 / 435$ & $6661 / 0 / 566$ \\
\hline Goodness-of-fit on $F^{2}$ & 1.000 & 1.000 & 1.000 & 1.000 \\
\hline Final $R$ indices $[I>2 \sigma(I)]$ & $R 1=0.0237, \mathrm{w} R 2=0.0620$ & $R 1=0.0337, \mathrm{w} R 2=0.0682$ & $R 1=0.0596, \mathrm{w} R 2=0.1683$ & $R 1=0.0340, \mathrm{w} R 2=0.0572$ \\
\hline$R$ indices (all data) & $R 1=0.0257, \mathrm{w} R 2=0.0624$ & $R 1=0.0459, \mathrm{w} R 2=0.0700$ & $R 1=0.0809, \mathrm{w} R 2=0.1745$ & $R 1=0.0539, \mathrm{w} R 2=0.0592$ \\
\hline Absolute structure parameter (Flack parameter) & $0.01(4)$ & $0.01(6)$ & $0.08(9)$ & $0.02(8)$ \\
\hline Largest diff. peak and hole $\left[\mathrm{e} \cdot \AA^{-3}\right]$ & 0.207 and -0.228 & 0.424 and -0.252 & 0.447 and -0.309 & 0.260 and -0.197 \\
\hline
\end{tabular}


Previously-known single-crystal X-ray diffraction data of compound $(S)-\mathbf{1} \cdot \mathrm{HCl}$ correspond to the chloroform adduct $(S)-\mathbf{1} \cdot \mathrm{HCl} \cdot \mathrm{CHCl}_{3}$ [1]. After recrystallization of compound $(S)-\mathbf{1} \cdot \mathrm{HCl}$ from methanol, single crystals of the methanol including compound $(S)-\mathbf{1} \cdot \mathrm{HCl} \cdot \mathrm{MeOH}$ were obtained (Figure 3 and Table 1). Compound (S)-1. $\mathrm{HCl} \cdot \mathrm{MeOH}$ crystallized in the orthorhombic crystal system, space group $P 2_{1} 2_{1} 2_{1}$, as colorless needles. The chloride ion is involved in hydrogen bond interactions with $\mathrm{H}(1 \mathrm{~N}), \mathrm{H}(2 \mathrm{~N})$, and the methanol hydroxyl group, with the $\mathrm{O}-\mathrm{H}(1 \mathrm{O}) \cdots \mathrm{Cl}$ hydrogen-bond $[\mathrm{O}-\mathrm{H}(1 \mathrm{O})$ $1.034 \AA, \mathrm{H}(1 \mathrm{O}) \cdots \mathrm{Cl} 2.071 \AA, \mathrm{O} \cdots \mathrm{Cl} 3.086 \AA, \mathrm{O}-\mathrm{H}(1 \mathrm{O}) \cdots \mathrm{Cl} 166.42^{\circ}$ ] being essential for the formation of a defined inclusion compound. In addition, a short distance of $3.651 \AA$ between chloride and the phenyl carbon atom $\mathrm{C}(14)$ gives a hint for a weak $\mathrm{C}(14)-\mathrm{H}(14) \cdots \mathrm{Cl}$ interaction within the crystal structure of (S)-1· $\mathrm{HCl} \cdot \mathrm{MeOH}$ (Figure 3).

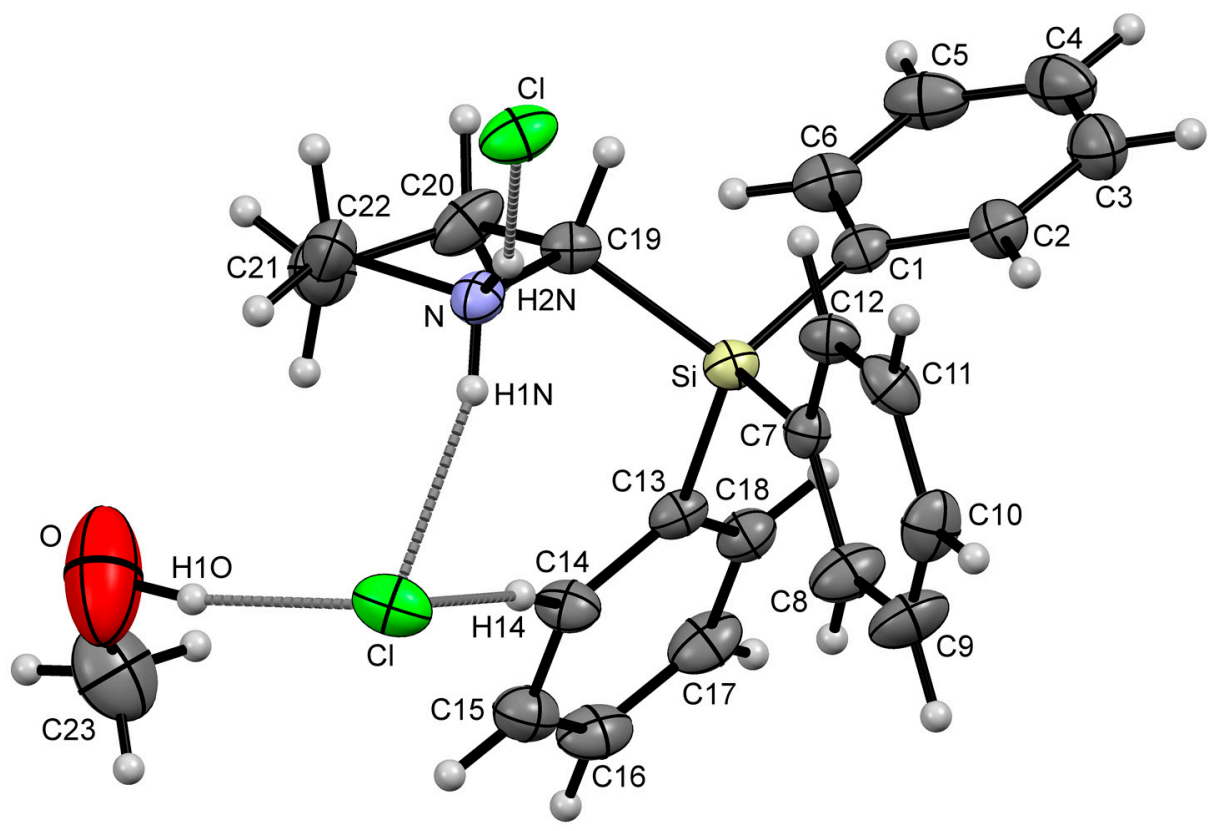

Figure 3. Part of the crystal structure (ORTEP plot) of compound (S)-1.HCl.MeOH in the crystal, with the displacement ellipsoids set at the $50 \%$ probability level. Selected bond lengths $(\AA)$ and angles $\left(^{\circ}\right)$ : C(1)-Si 1.863(2), C(7)-Si 1.870(2), C(13)-Si 1.873(2), C(19)-Si 1.905(2), C(19)-N 1.498(3), C(22)-N 1.494(3), O-C(23) 1.385(3), C(13)-Si-C(7) 112.48(9), C(13)-Si-C(1) 108.46(9), C(7)-Si-C(1) 110.86(9), C(13)-Si-C(19) 110.34(9), C(7)-Si-C(19) 108.18(9), C(1)-Si-C(19) 106.34(9). Hydrogen bond $\mathrm{N}-\mathrm{H}(1 \mathrm{~N}) \cdots \mathrm{Cl}: \mathrm{N}-\mathrm{H}(1 \mathrm{~N})$ 0.870, $\mathrm{H}(1 \mathrm{~N}) \cdots \mathrm{Cl} 2.310, \mathrm{~N} \cdots \mathrm{Cl} 3.125, \mathrm{~N}-\mathrm{H}(1 \mathrm{~N}) \cdots \mathrm{Cl}$ 155.93. Hydrogen bond $\mathrm{N}-\mathrm{H}(2 \mathrm{~N}) \cdots \mathrm{Cl}: \mathrm{N}-\mathrm{H}(2 \mathrm{~N})$ 0.913, $\mathrm{H}(2 \mathrm{~N}) \cdots \mathrm{Cl} 2.184, \mathrm{~N} \cdots \mathrm{Cl} 3.062, \mathrm{~N}-\mathrm{H}(2 \mathrm{~N}) \cdots \mathrm{Cl} 160.99$. Hydrogen bond

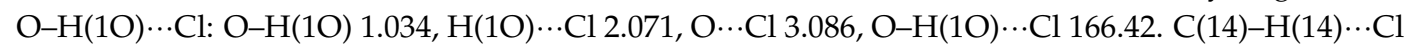
interaction: $\mathrm{C}(14) \cdots \mathrm{Cl} 3.651, \mathrm{C}(14)-\mathrm{H}(14) \cdots \mathrm{Cl} 171.50$. Symmetry transformations used to generate the equivalent methanol molecule: $x, 1+y, 1+z$. Symmetry transformations used to generate the equivalent atom $\mathrm{Cl}$, hydrogen-bonded to $\mathrm{H}(2 \mathrm{~N}): \frac{1}{2}+x, 1.5-y, 2-z$.

Compound (S)-2. $\mathrm{HClO}_{4}$ crystallized in the monoclinic crystal system, space group $P 2_{1}$, as colorless plates (Figure 4 and Table 1 ). The asymmetric unit of compound (S)-2. $\mathrm{HClO}_{4}$ contains two independent molecules $\left[(S)-2 \cdot \mathrm{HClO}_{4}-\mathbf{A}\right.$ and $\left.(S)-\mathbf{2} \cdot \mathrm{HClO}_{4}-\mathbf{B}\right]$. The bond lengths between the silyl group and the heterocycle with 1.878(5) $\AA$ [C(14)-Si(1), molecule A] and 1.889(5) $\AA$ [C(31)-Si(2), molecule B] differ slightly from each other, but are considerably shorter than the respective bond in the 2-triphenylsilyl derivative (S)-1. $\cdot \mathrm{HClO}_{4}$ (compare Figures 2 and 4). The $\mathrm{C}-\mathrm{Si}-\mathrm{C}$ angles are in both independent molecules very close to the ideal tetrahedral angle (Figure 4). 


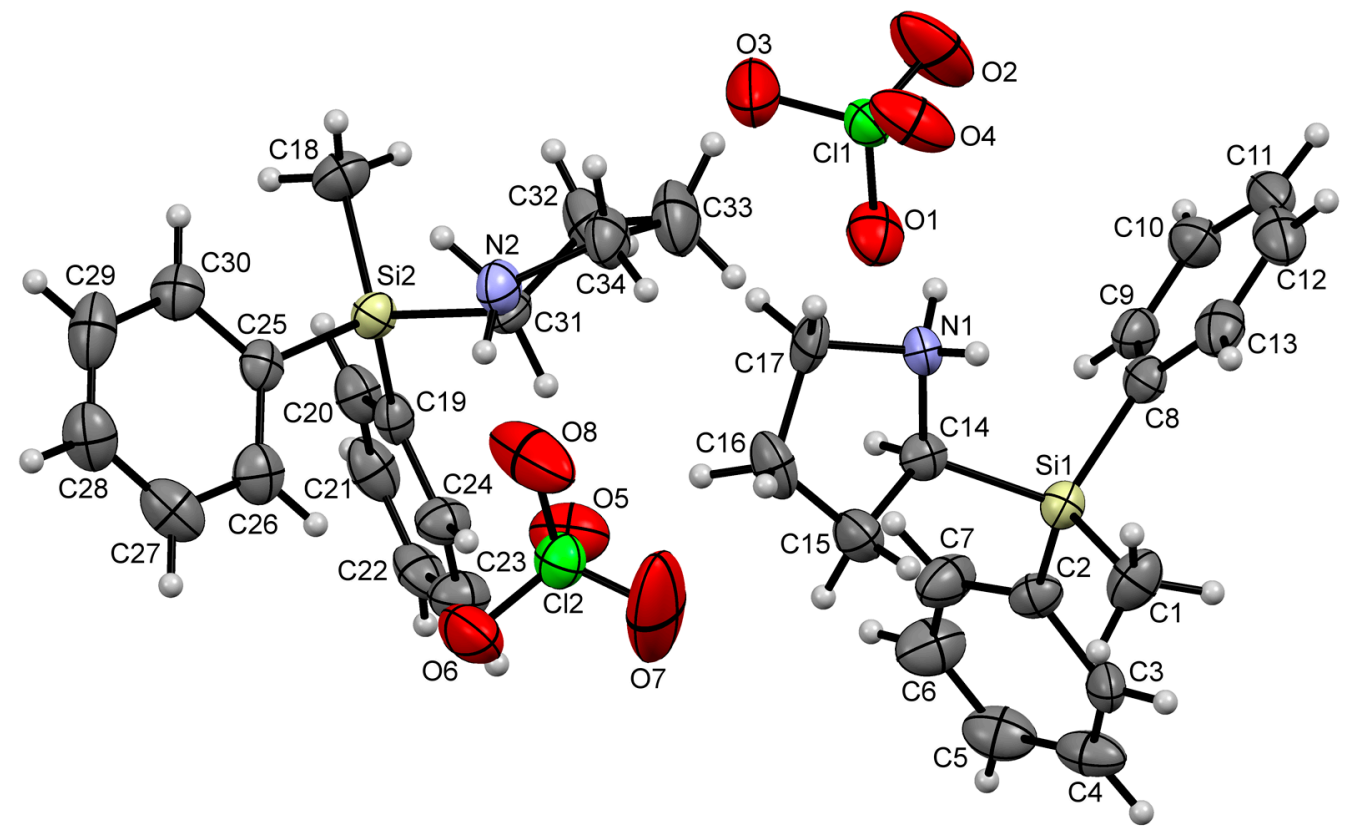

Figure 4. Molecular structure (ORTEP plot) of compound (S)-2. $\mathrm{HClO}_{4}$ in the crystal, with the displacement ellipsoids set at the $50 \%$ probability level. Selected bond lengths $(\AA)$ and angles $\left({ }^{\circ}\right)$ : Molecule (S)-2. $\mathrm{HClO}_{4}$-A: C(1)-Si(1) 1.852(6), C(2)-Si(1) 1.855(6), C(8)-Si(1) 1.871(5), C(14)-Si(1) 1.878(5), C(14)-N(1) 1.508(7), C(17)-N(1) 1.508(6), Cl(1)-O(1) 1.416(4), Cl(1)-O(2) 1.413(5), Cl(1)-O(3) 1.426(5), Cl(1)-O(4) 1.413(5), C(1)-Si(1)-C(2) 112.5(3), C(1)-Si(1)-C(8) 109.7(3), C(2)-Si(1)-C(8) 110.6(2), C(1)-Si(1)-C(14) 109.4(3), C(2)-Si(1)-C(14) 106.4(2), C(8)-Si(1)-C(14) 108.1(2). Molecule (S)-2.HClO 4 -B: C(18)-Si(2) 1.856(6), C(19)-Si(2) 1.875(6), C(25)-Si(2) 1.884(5), C(31)-Si(2) 1.889(5), C(31)-N(2) 1.509(7), $\mathrm{C}(34)-\mathrm{N}(2)$ 1.510(7), $\mathrm{Cl}(2)-\mathrm{O}(5)$ 1.400(5), $\mathrm{Cl}(2)-\mathrm{O}(6)$ 1.405(5), Cl(2)-O(7) 1.365(6), Cl(2)-O(8) 1.431(5), $\mathrm{C}(18)-\mathrm{Si}(2)-\mathrm{C}(19) 109.9(3), \mathrm{C}(18)-\mathrm{Si}(2)-\mathrm{C}(25)$ 111.5(3), C(19)-Si(2)-C(25) 110.1(2), C(18)-Si(2)-C(31) 110.4(3), C(19)-Si(2)-C(31) 106.0(2), C(25)-Si(2)-C(31) 108.8(2).

Treatment of enantiomerically-enriched (S)-2-(methyldiphenylsilyl)pyrrolidine [(S)-2] with trifluoroacetic acid in dichloromethane resulted in the formation of the trifluoroacetate (S)-2.TFA. Enantiomerically-pure single crystals of (S)-2.TFA were obtained after recrystallization from acetonitrile. Compound (S)-2.TFA crystallized in the orthorhombic crystal system, space group $P 2_{1} 2_{1} 2_{1}$, as colorless needles (Figure 5 and Table 1 ). Like in the perchlorate $(S)-2 \cdot \mathrm{HClO}_{4}$ (see Figure 4 ) and in the hydrochloride $(S)-\mathbf{2} \cdot \mathrm{HCl}$ [1], the asymmetric unit of compound (S)-2.TFA contains two independent molecules [(S)-2.TFA-A and (S)-2.TFA-B]. The fluorine atoms of the trifluoroacetate anions and the pyrrolidine carbon atom C(35) of molecule (S)-2-TFA-B are disordered. Each trifluoroacetate is hydrogen-bonded to two silylpyrrolidinium cations via an $\mathrm{N}-\mathrm{H} \cdots \mathrm{O}$ interaction. The parameters of the found hydrogen-bonds differ from each other, with the $\mathrm{N}-\mathrm{H}$ distances ranging from $0.847 \AA[\mathrm{N}(2)-\mathrm{H}(4 \mathrm{~N})]$ to $1.082 \AA[\mathrm{N}(2)-\mathrm{H}(3 \mathrm{~N})]$, and the $\mathrm{N}-\mathrm{H} \cdots \mathrm{O}$ angles ranging from $159.48^{\circ}$ $[\mathrm{N}(1)-\mathrm{H}(2 \mathrm{~N}) \cdots \mathrm{O}(2)]$ to $172.31^{\circ}[\mathrm{N}(2)-\mathrm{H}(3 \mathrm{~N}) \cdots \mathrm{O}(3)]$, although the $\mathrm{N} \cdots \mathrm{O}$ distances are quite similar (Figure 5). 


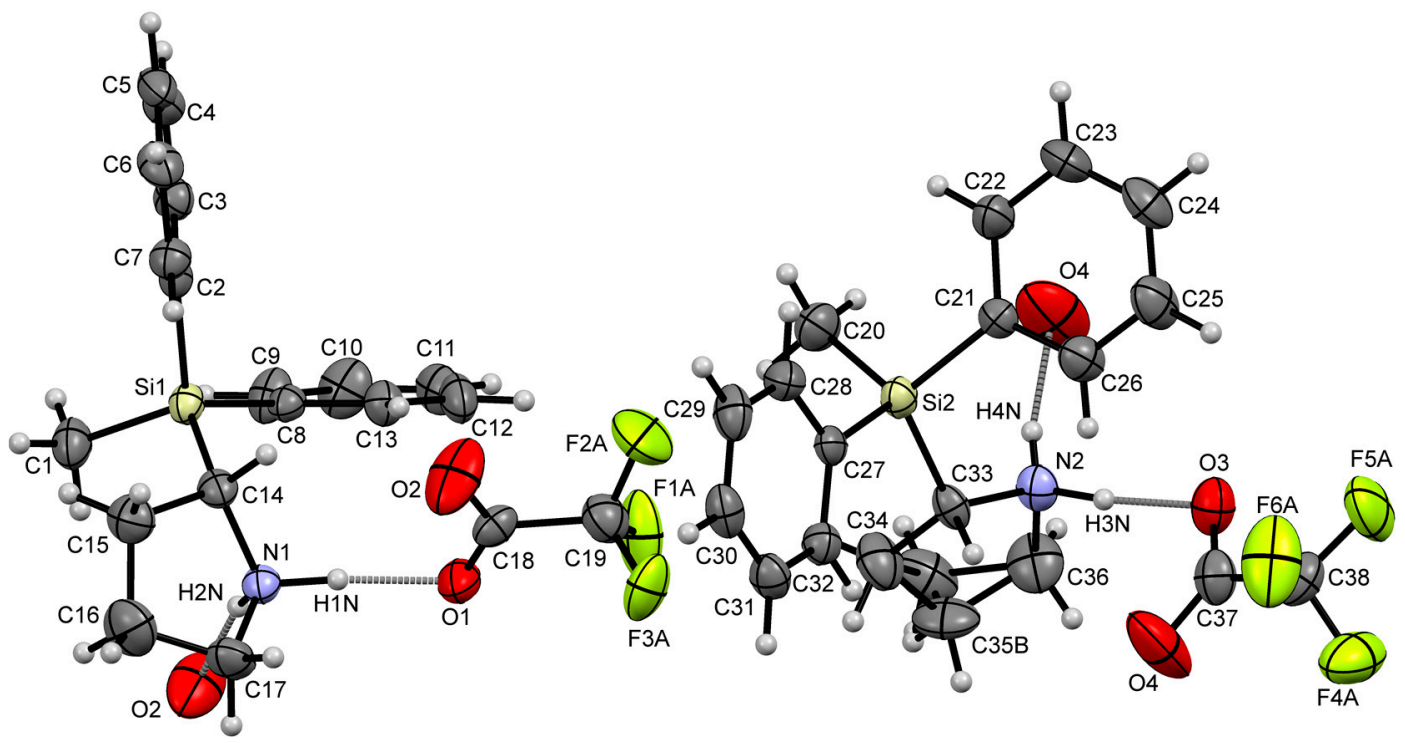

Figure 5. Part of the crystal structure (ORTEP plot) of compound (S)-2.TFA in the crystal, with the displacement ellipsoids set at the $50 \%$ probability level. The ellipsoids $\mathrm{F}(1 \mathrm{~B}), \mathrm{F}(2 \mathrm{~B})$, and $\mathrm{F}(3 \mathrm{~B})$ of molecule (S)-2-TFA-A, and the ellipsoids F(4B), F(5B), and F(6B) of (S)-2-TFA-B are omitted for clarity. Selected bond lengths $(\AA)$ and angles $\left(^{\circ}\right)$ : Molecule (S)-2.TFA-A: C(1)-Si(1) 1.849(2), C(2)-Si(1) 1.863(2), C(8)-Si(1) 1.857(2), C(14)-Si(1) 1.889(2), C(14)-N(1) 1.505(2), C(17)-N(1) 1.491(3), C(18)-C(19) 1.520(3), C(18)-O(1) 1.225(3), C(18)-O(2) 1.206(3), C(1)-Si(1)-C(2) 111.77(10), C(1)-Si(1)-C(8) 110.07(10), C(2)-Si(1)-C(8) 108.11(9), C(1)-Si(1)-C(14) 109.69(10), C(2)-Si(1)-C(14) 107.16(10), C(8)-Si(1)-C(14) 109.98(9). Hydrogen bond $\mathrm{N}(1)-\mathrm{H}(1 \mathrm{~N}) \cdots \mathrm{O}(1)$ : $\mathrm{N}(1)-\mathrm{H}(1 \mathrm{~N}) 1.050, \mathrm{H}(1 \mathrm{~N}) \cdots \mathrm{O}(1) 1.680, \mathrm{~N}(1) \cdots \mathrm{O}(1)$ 2.716, $\mathrm{N}(1)-\mathrm{H}(1 \mathrm{~N}) \cdots \mathrm{O}(1)$ 167.81. Hydrogen bond $\mathrm{N}(1)-\mathrm{H}(2 \mathrm{~N}) \cdots \mathrm{O}(2): \mathrm{N}(1)-\mathrm{H}(2 \mathrm{~N}) 1.010, \mathrm{H}(2 \mathrm{~N}) \cdots \mathrm{O}(2)$ $1.769, \mathrm{~N}(1) \cdots \mathrm{O}(2) 2.738, \mathrm{~N}(1)-\mathrm{H}(2 \mathrm{~N}) \cdots \mathrm{O}(2)$ 159.48. Symmetry transformations used to generate the equivalent atom $\mathrm{O}(2)$, hydrogen-bonded to $\mathrm{H}(2 \mathrm{~N}): 1-x,-\frac{1}{2}+y, \frac{1}{2}-z$. Molecule (S)-2.TFA-B: C(20)-Si(2) 1.845(2), C(21)-Si(2) 1.850(2), C(27)-Si(2) 1.851(2), C(33)-Si(2) 1.884(2), C(33)-N(2) 1.507(3), $\mathrm{C}(36)-\mathrm{N}(2) 1.491(3), \mathrm{C}(37)-\mathrm{C}(38) 1.522(3), \mathrm{C}(37)-\mathrm{O}(3) 1.220(3), \mathrm{C}(37)-\mathrm{O}(4) 1.205(3), \mathrm{C}(20)-\mathrm{Si}(2)-\mathrm{C}(21)$ 110.03(11), C(20)-Si(2)-C(27) 110.46(10), C(21)-Si(2)-C(27) 108.38(9), C(20)-Si(2)-C(33) 111.26(11), $\mathrm{C}(21)-\mathrm{Si}(2)-\mathrm{C}(33)$ 110.30(9), C(27)-Si(2)-C(33) 106.30(10). Hydrogen bond $\mathrm{N}(2)-\mathrm{H}(3 \mathrm{~N}) \cdots \mathrm{O}(3)$ : $\mathrm{N}(2)-\mathrm{H}(3 \mathrm{~N}) 1.082, \mathrm{H}(3 \mathrm{~N}) \cdots \mathrm{O}(3)$ 1.665, $\mathrm{N}(2) \cdots \mathrm{O}(3) 2.740, \mathrm{~N}(2)-\mathrm{H}(3 \mathrm{~N}) \cdots \mathrm{O}(3)$ 172.31. Hydrogen bond $\mathrm{N}(2)-\mathrm{H}(4 \mathrm{~N}) \cdots \mathrm{O}(4): \mathrm{N}(2)-\mathrm{H}(4 \mathrm{~N})$ 0.847, $\mathrm{H}(4 \mathrm{~N}) \cdots \mathrm{O}(4)$ 1.903, $\mathrm{N}(2) \cdots \mathrm{O}(4) 2.728, \mathrm{~N}(2)-\mathrm{H}(4 \mathrm{~N}) \cdots \mathrm{O}(4) 164.58$. Symmetry transformations used to generate the equivalent trifluoroacetate anion, hydrogen-bonded to $\mathrm{H}(3 \mathrm{~N}): \frac{1}{2}+x, 1.5-y, 1-z$. Symmetry transformations used to generate the equivalent atom $\mathrm{O}(4)$, hydrogen-bonded to $\mathrm{H}(4 \mathrm{~N}): 1+x, y, z$.

\section{Experimental Details}

\subsection{Synthetic Methods}

Synthesis and characterization data of compounds $(S)-\mathbf{1} \cdot \mathrm{HCl}$ and $(S)-\mathbf{2} \cdot \mathrm{HCl}$ were previously reported by our group [1]. The perchlorate salts $(S)-\mathbf{1} \cdot \mathrm{HClO}_{4}$ and $(S)-\mathbf{2} \cdot \mathrm{HClO}_{4}$ were prepared by treatment of $(S)-\mathbf{1} \cdot \mathrm{HCl}$ and $(S)-\mathbf{2} \cdot \mathrm{HCl}$, respectively, with excess perchloric acid (60 wt \%). Colorless single-crystals were formed overnight under normal atmosphere at room temperature within the remaining solvent. Single crystals of the inclusion compound (S)-1.HCl.MeOH were obtained after recrystallization of $(S)-\mathbf{1} \cdot \mathrm{HCl}$ from methanol. (S)-2.TFA was prepared by treatment of $800 \mathrm{mg}$ (2.99 mmol) enantiomerically-enriched (S)-2-(methyldiphenylsilyl)pyrrolidine [(S)-2, e.r. = 89:11] with $341 \mathrm{mg}$ (2.99 mmol) trifluoroacetic acid in $10 \mathrm{~mL}$ dichloromethane at room temperature. After removing of all volatiles in vacuo, the residue was dissolved in acetonitrile. Enantiomerically-pure single crystals of $(S)-2$.TFA were formed under normal atmosphere at room temperature within three months. 


\subsection{X-ray Crystallography}

Single-crystal X-ray diffraction analyses were performed on an Oxford Diffraction Xcalibur S diffractometer (Oxford Diffraction Ltd. (Abingdon, UK)) at 173(2) K using graphite-monochromated Mo $K \alpha$ radiation $(\lambda=0.71073 \AA)$. The crystals were mounted at room temperature. The crystal structures were solved with direct methods (SHELXS-97 [11]) and refined against $F^{2}$ with the full-matrix least-squares method (SHELXL-97 [12,13]). A multi-scan absorption correction using the implemented CrysAlis RED program (Version 1.171.32.37, Oxford Diffraction Ltd.) was employed. The non-hydrogen atoms were refined anisotropically. The hydrogen atoms $\mathrm{H}(1 \mathrm{~N})$ and $\mathrm{H}(2 \mathrm{~N})$ in compound $(S)-\mathbf{1} \cdot \mathrm{HClO}_{4}, \mathrm{H}(1 \mathrm{~N}), \mathrm{H}(2 \mathrm{~N})$, and $\mathrm{H}(1 \mathrm{O})$ in compound $(S)-\mathbf{1} \cdot \mathrm{HCl} \cdot \mathrm{MeOH}$, and $\mathrm{H}(1 \mathrm{~N})$, $\mathrm{H}(2 \mathrm{~N}), \mathrm{H}(3 \mathrm{~N}), \mathrm{H}(4 \mathrm{~N}), \mathrm{H}(34 \mathrm{~A}), \mathrm{H}(34 \mathrm{~B}), \mathrm{H}(36 \mathrm{~A})$, and $\mathrm{H}(36 \mathrm{~B})$ in compound (S)-2.TFA were located on the difference Fourier map and refined independently. All other hydrogen atoms were placed in geometrically-calculated positions and each was assigned a fixed isotropic displacement parameter based on a riding model. The fluorine atoms $\mathrm{F}(1)-\mathrm{F}(6)$ and the carbon atom $\mathrm{C}(35)$ in (S)-2.TFA are disordered. The absolute configuration of $(S)-\mathbf{1} \cdot \mathrm{HClO}_{4},(S)-\mathbf{1} \cdot \mathbf{H C l} \cdot \mathrm{MeOH},(S)-\mathbf{2} \cdot \mathrm{HClO}_{4}$, and (S)-2.TFA was determined by Flack's method based on resonant scattering [14]. Figures 2-5 were created using Mercury (Version 3.3). Crystal and refinement data are collected in Table 1. Crystallographic data of enantiomerically-pure 2-silylpyrrolidinium salts $(S)-\mathbf{1} \cdot \mathrm{HClO}_{4},(S)-\mathbf{2} \cdot \mathrm{HClO}_{4},(S)-\mathbf{1} \cdot \mathbf{H C l} \cdot \mathbf{M e O H}$, and (S)-2.TFA have been deposited with The Cambridge Crystallographic Data Centre. CCDC 1582443

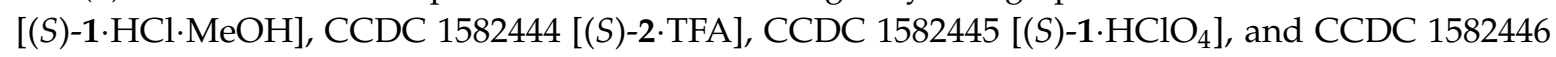
$\left[(S)-\mathbf{2} \cdot \mathrm{HClO}_{4}\right]$ contain the supplementary crystallographic data for this paper (see Supplementary Materials). These data can be obtained free of charge via http://www.ccdc.cam.ac.uk/conts/ retrieving.html (or from the CCDC, 12 Union Road, Cambridge CB2 1EZ, UK; Fax: +44 1223 336033; E-mail: deposit@ccdc.cam.ac.uk).

\section{Conclusions}

In the context of studies concerning the effect of the counter anion in organocatalytic reactions with polar species involved, we were interested to synthesize salts of optically-pure 2-silylpyrrolidines with different counter anions for further reactivity studies, which might be of interest in terms of hydrogen-bond activation in the initial enamine formation step. By studying the hydrogen-bonding behavior of 2-silylpyrrolidines, interesting information about silicon-specific effects on the basicity of the pyrrolidine nitrogen center may be provided. Future studies will also address the respective salts of the carbon analogue 2-tritylpyrrolidine for comparison.

Supplementary Materials: The following are available online at www.mdpi.com/2304-6740/5/4/88/s1. Cif and cif-checked files.

Acknowledgments: This research was supported by the Deutsche Forschungsgemeinschaft (DFG). Jonathan O. Bauer thanks the Alexander von Humboldt Foundation for the award of a Feodor Lynen Return Fellowship.

Author Contributions: Jonathan O. Bauer performed the experiments and wrote the manuscript. Carsten Strohmann was coordinating the project and performed the XRD analyses.

Conflicts of Interest: The authors declare no conflict of interest.

\section{References}

1. Bauer, J.O.; Stiller, J.; Marqués-López, E.; Strohfeldt, K.; Christmann, M.; Strohmann, C. Silyl-modified analogues of 2-tritylpyrrolidine: Synthesis and applications in asymmetric organocatalysis. Chem. Eur. J. 2010, 16, 12553-12558. [CrossRef] [PubMed]

2. Husmann, R.; Jörres, M.; Raabe, G.; Bolm, C. Silylated pyrrolidines as catalysts for asymmetric Michael additions of aldehydes to nitroolefins. Chem. Eur. J. 2010, 16, 12549-12552. [CrossRef] [PubMed] 
3. Jentzsch, K.I.; Min, T.; Etcheson, J.I.; Fettinger, J.C.; Franz, A.K. Silyl fluoride electrophiles for the enantioselective synthesis of silylated pyrrolidine catalysts. J. Org. Chem. 2011, 76, 7065-7075. [CrossRef] [PubMed]

4. Min, T.; Fettinger, J.C.; Franz, A.K. Enantiocontrol with a hydrogen-bond directing pyrrolidinylsilanol catalyst. ACS Catal. 2012, 2, 1661-1666. [CrossRef]

5. Kerrick, S.T.; Beak, P. Asymmetric deprotonations: Enantioselective syntheses of 2-substituted (tert-butoxycarbonyl)pyrrolidines. J. Am. Chem. Soc. 1991, 113, 9708-9710. [CrossRef]

6. Strohfeldt, K.; Seibel, T.; Wich, P.; Strohmann, C. Synthesis and reactivity of an enantiomerically pure N-methyl-2-silyl-substituted pyrrolidine. In Organosilicon Chemistry VI: From Molecules to Materials; Auner, N., Weis, J., Eds.; Wiley-VCH: Weinheim, Germany, 2005; Volume 1, pp. 488-494.

7. Kano, T.; Mii, H.; Maruoka, K. Direct asymmetric benzoyloxylation of aldehydes catalyzed by 2-tritylpyrrolidine. J. Am. Chem. Soc. 2009, 131, 3450-3451. [CrossRef] [PubMed]

8. Erdmann, H.; An, F.; Mayer, P.; Ofial, A.R.; Lakhdar, S.; Mayr, H. Structures and reactivities of 2-trityland 2-(triphenylsilyl)pyrrolidine-derived enamines: Evidence for negative hyperconjugation with the trityl group. J. Am. Chem. Soc. 2014, 136, 14263-14269. [CrossRef] [PubMed]

9. Bauer, J.O.; Strohmann, C. tert-Butoxytriphenylsilane. Acta Crystallogr. 2010, E66, o461-o462. [CrossRef] [PubMed]

10. Brendler, E.; Heine, T.; Seichter, W.; Wagler, J.; Witter, R. ${ }^{29}$ Si NMR shielding tensors in triphenylsilanes- ${ }^{29} \mathrm{Si}$ solid state NMR experiments and DFT-IGLO calculations. Z. Anorg. Allg. Chem. 2012, 638, 935-944. [CrossRef]

11. Sheldrick, G.M. SHELXS-97, a Program for the Solution of Crystal Structures; Universität Göttingen: Göttingen, Germany, 1997.

12. Sheldrick, G.M. SHELXL-97, a Program for Crystal Structure Refinement; Universität Göttingen: Göttingen, Germany, 1997.

13. Sheldrick, G.M. A short history of SHELX. Acta Crystallogr. 2008, A64, 112-122. [CrossRef] [PubMed]

14. Flack, H.D.; Bernardinelli, G. The use of X-ray crystallography to determine absolute configuration. Chirality 2008, 20, 681-690. [CrossRef] [PubMed]

(C) 2017 by the authors. Licensee MDPI, Basel, Switzerland. This article is an open access article distributed under the terms and conditions of the Creative Commons Attribution (CC BY) license (http:/ / creativecommons.org/licenses/by/4.0/). 